\title{
DYKE DAVIDOFF MASSON SYNDROME (DDMS)-A rare case
}

Yaumi Faiza, ${ }^{1}$ Syarif Indra ${ }^{2}$

\begin{abstract}
Abstrak
Dyke Davidoff Mason Syndrome (DDMS) merupakan suatu kasus jarang yang memperlihatkan adanya atrofi pada satu hemisfer serebral (hemiatrofi). Sindrom ini terjadi karena gangguan perkembangan otak pada periode fetal atau periode awal kehidupan. Gejala klinis bervariasi pada setiap individu, dipengaruhi oleh seberapa luas kerusakan otak yang terlibat. Gejala klinis yang paling sering terjadi adalah kejang berulang, wajah asimetris, hemiparese kontralateral, retardasi mental, gangguan belajar, gangguan bicara dan bahasa. Gangguan sensorik dan gejala psikiatri seperti skizofrenia dapat terjadi, namun jarang dilaporkan. Gambaran radiologi berupa hemiatrofi serebral. Dilaporkan seorang laki-laki berumur 17 tahun dating dengan status epileptikus, hemiparese sinistra, parese nervus VII dan XII sinistra tipe sentral, gangguan tumbuh kembang, dan gangguan belajar. Pada pemeriksaan MRI otak ditemukan gambaran hemiatrofi serebri dekstra dan gliosis serta porencephalic cyst besar di kanan posterior yang mendukung kearah diagnosis Dyke Davidoff Mason Syndrome (DDMS).
\end{abstract}

Kata Kunci: Dyke Davidoff Mason syndrome, kejang, hemiatrofi serebral

\begin{abstract}
Dyke Davidoff Mason Syndrome (DDMS) is a rare case that shows cerebral hemiatrophy. It is caused by an impaired brain development of fetal phase. Clinical features are variety, depending on the brain damage involved. The most common symptom are seizures, asimmetrical face, contralateral hemipharesis, mental retardation, impairment the ability to speak. Sensoric and psychiatry symptoms can rarely happen. Imaging shows an cerebral hemiatrophy. It was reported an unusual case of Dyke Davidoff Mason Syndrome in a 17-year-old boy who presents status epilepticus, left hemipharesis, $7^{\text {th }}$ and $12^{\text {th }}$ cranial nerve palsy, developmental impairment, and disability of learning. Brain MRI shows right hemiatrophy cerebral and gliosis and right posterior porencephalic cyst that support to diagnose Dyke Davidoff Mason Syndrome.
\end{abstract}

Key words: Dyke Davidoff Mason syndrome, seizures, hemiatrophy cerebral

Affiliasi penulis: 1. Pendidikan Dokter Spesialis Neurologi, Fakultas Kedokteran, Universitas Andalas, Padang, Indonesia. 2. Bagian Neurologi, , Fakultas Kedokteran, Universitas Andalas, Padang, Indonesia.

Korespondensi: SyarifIndra, Email: indraneuro@yahoo.com Telp/HP:082173044099

\section{PENDAHULUAN}

Dyke Davidoff Mason Syndrome (DDMS) pertama kali dilaporkan pada tahun 1933, merupakan suatu kasus yang sangat jarang, sehingga diagnosis sulit terdeteksi oleh klinisi, dan mengaburkan diagnosis penyakit ini dengan penyakit lain. Kelainan penyakit ini memperlihatkan adanya atrofi pada satu hemisfer serebral (hemiatrofi). ${ }^{1}$ Sindrom ini terjadi karena gangguan perkembangan otak pada periode fetal atau periode awal kehidupan. ${ }^{2}$ Gejala klinis bervariasi pada setiap individu, dipengaruhi oleh seberapa luas kerusakan otak yang terlibat. Gejala klinis yang paling sering terjadi adalah kejang berulang, wajah asimetris, hemiparese kontralateral, retardasi mental atau gangguan belajar dan gangguan bicara dan bahasa. Gangguan sensorik dan gejala psikiatri seperti skizofrenia dapat terjadi, namun jarang dilaporkan ${ }^{3}$. Gambaran radiologi berupa hemiatrofi serebral dengan hipertropi tulang dan sinus pada sisi yang sama sebagai reaksi kompensasi. Diagnosis biasanya diketahui pada saat pasien berumur belasan atau dewasa. ${ }^{4}$ Namun juga bisa terdeteksi di umur 
anak-anak. ${ }^{5}$ Pada kasus ini kami melaporkan pasien laki-laki berusia 17 tahun dengan gejala klinis dan gambaran radiologi mengarah kepada diagnosis DDMS. Oleh sebab itu diperlukan anamnesis yang tepat, pemeriksaan fisik dan pemeriksaan penunjang yang dapat membantu klinisi dalam menegakkan diagnosis ini, meskipun penyakit ini jarang terjadi.

\section{KASUS}

Seorang pasien laki-laki berumur 17 tahun dating ke IGD RS.Dr.M.Djamil Padang 3 jam sebelum masuk RS, dengan kejang umum tonik klonik. Kejang berulang dengan pola yang sama, frekuensi 5-6 kali, jarak antara kejang \pm 1 jam.

Pasien didiagnosis status epileptikus pada saat masuk, dengan kelelahan sebagai faktor pemicu. Pasien memiliki riwayat kejang umum tonik klonik sejak berumur 3 bulan. Pasien mendapat terapi anti epilepsi karbamazepin 2x200mg. Namun kejang tetap berulang, sehingga dosis dinaikkan hingga 2x400 mg. Kejang tetap terjadi 1-2 kali sebulan. Sekitar 1 tahun yang lalu, karbamazepin diganti dengan asam valproate $2 \times 500 \mathrm{mg}$ dan luminal $2 \times 60 \mathrm{mg}$, berobat rutin dan tidak pernah putus obat. Namun kejang masih berulang dengan frekuensi 1-2 kali/bulan. Mulut mencong, bicara pelo dan kelemahan anggota gerak kiri sejak umur 1 tahun, dimana pasien sekarang berjalan dengan menyeret kaki kiri. Pasien mengalami keterlambatan tumbuh kembang dimana bisa berjalan umur 3 tahun dengan menyeret, dan bisa bicara per kata umur 2,5 tahun. Pasien mengalami kesulitan dalam belajar. Tidak ada riwayat anggota keluarga yang menderita kejang. Riwayat persalinan pervaginam, bayi langsung menangis, cukup bulan dengan berat badan lahir 3,1 kg. Selama kehamilan, ibu pasien kontrol teratur kebidan, tidak ada penyakit infeksi, dan tidak ada riwayat trauma. Pada pemeriksaan fisik setelah kejang teratasi, didapatkan kesadaran composmentis kooperatif, parese N. VII dan XII sinistra tipe sentral. Kelemahan anggota gerak kiri dengan kekuatan 444 ekstremitas atas, dan 333 ekstremitas bawah. Terdapat peningkatan reflek fisiologis pada anggota gerak kiri, dan babinski positif di tungkai kiri.Tidak ada tanda rangsangan meningeal, tidak ada gangguan sensorik, dan gangguan otonom.
Pemeriksaan biokimia darah, termasuk fungsi hati dan ginjal dalam batas normal. Glukosa darah sewaktu, elektrolit darah $(\mathrm{Na}, \mathrm{K}, \mathrm{Cl}, \mathrm{Ca})$ dalam batas normal.
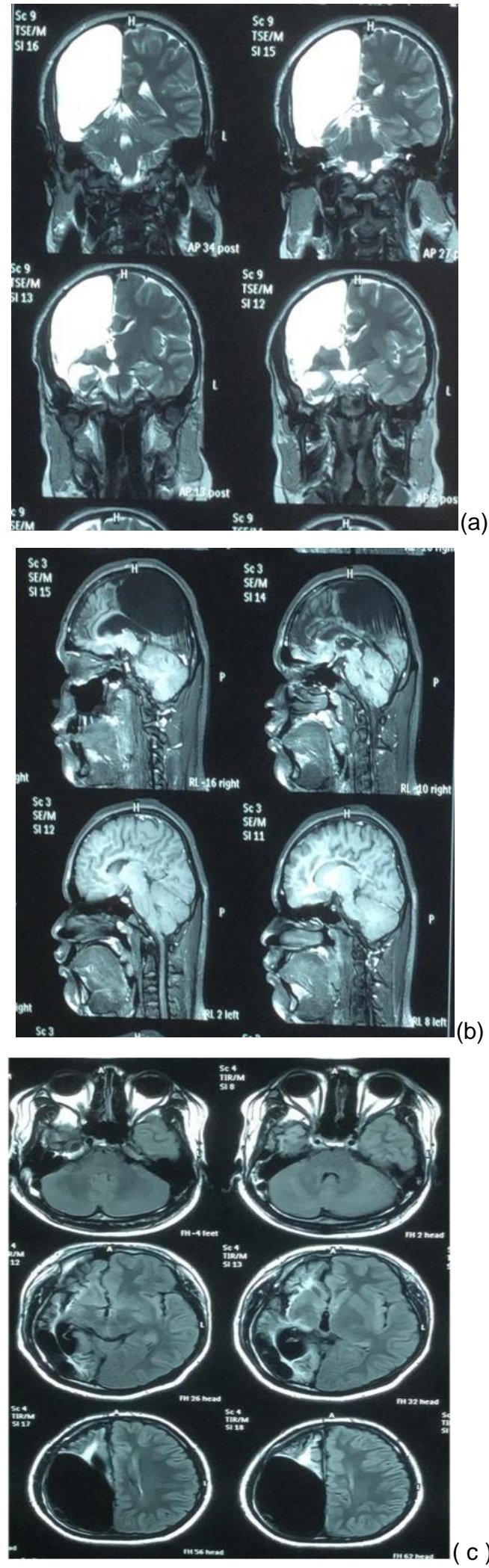

Gambar 1. brain MRI T1 (a) dan T2 (b) dan Flair (c). 
Pemeriksaan MRI otak dilakukan satu bulan sebelum masuk RS, dengan hasil ditemukan hemiatrofi cerebral kanan dengan gliosis dan porencephalic cyst besar di kanan posterior. Dilatasi ventrikel lateral kanan dengan porencephalic cyst. Terdapat penebalan tulang calvaria di frontal kanan. (gambar 1). Dari anamnesis, pemeriksaan fisik dan pemeriksaan penunjang dengan pemeriksaan MRI kepala dapat ditegakkan diagnosis DDMS.

Pasien diberikan fenitoin drip $15 \mathrm{mg} / \mathrm{kg}$ BB (1350 mg) untuk mengatasi status epileptikus. Setelah itu kejang tidak muncul lagi, dan diberikan dosis fenitoin $3 \times 100 \mathrm{mg}$ (intra vena), dansetelah 36 jam bebas kejang, terapi diganti menjadi fenitoin 3x100 mg (per oral). Pasien dikonsulkan ke bagian bedah saraf, dan tidak ada tindakan operatif dari bagian bedah saraf. Pasien dipulangkan setelah 3 hari bebas kejang (3 hari rawatan), dan diberikan edukasi untuk tidak boleh putus obat epilepsi, dankontrol ke poli saraf.

\section{PEMBAHASAN}

Secara klinis DDMS ini mencakup asimetri fasial, kejang beruang, hemiparesis kontralateral, retardasi mental, dan gangguan belajar. Kejang dapat berupa fokal atau umum. Pada beberapa kasus, dapat dijumpai gangguan psikiatri. ${ }^{2}$

Penyebab DDMS adalah gangguan pada serebral, yang bisa terjadi pada periode prenatal, perinatal atau postnatal. Penyebab prenatal adalah malformasi kongenital, infeksi, gangguan vaskular. Penyebab perinatal, biasanya karena proses persalinan, dimana terjadi anoksia, hipoksia dan perdarahan intrakranial. Penyebab postnatal adalah trauma, tumor, infeksi dan kejang demam yang lama. ${ }^{6}$ Pada kasus ini ,DDMS terjadi pada periode prenatal, yaitu malformasi kongenital, berupa hemiatrofi serebral karena tidak ditemukan tanda-tanda infeksi ibu saat hamil, ataupun kelainan dan gangguan saat persalinan.

Hemiatrofi serebral ada 2 tipe, yaitu kongenital dan didapat. ${ }^{7}$ Diagnosis banding DDMS dapat berupa germinoma ganglia basal, Sturge Weber Syndrome, dan Rasmussen Ensefalitis. Dengan anamnesis dan pemeriksaan fisik yang baik dan ditunjang dengan pemeriksaan radiologi, DDMS dapat ditegakkan dan diagnosis banding dapat disingkirkan. ${ }^{8,9}$ Pada tipe kongenital biasanya disebabkan karena infeksi, oklusi vaskular saat kehamilan yang melibatkan A.serebri media, anomali sirkulasi arteri serebri unilateral. Pada tipe yang didapat terjadi pada periode perinatal atau infant, yang disebabkan oleh trauma, tumor, infeksi, iskemik, hemoragik, dan kejang demam yang lama. Munculan gejala klinis bisa saja terjadi setelah periode remaja atau dewasa. ${ }^{10}$

Pada perkembangan otak normal, setengah volume otak terbentuk selama setahun pertama kehidupan, dan $3 / 4$ nya terbentuk di akhir tahun ke 3 . Pada saat otak berkembang, jaringan otak tersebut akan menekan tulang, sehingga terjadi pembesaran yang gradual hingga tercapai bentuk dan besar kepala dewasa. Jika salah satu otak gagal berkembang, hemisfer lain akan menekan jaringan yang tidak berkembang tersebut. ${ }^{11}$

DDMS ditandai oleh atrofi atau hipoplasia satu hemisfer, adanya midline shift, hipertrofi tulang dengan hiperpneumatisasi sinus, terutama di frontal dan mastoid dengan paresis kontralateral. ${ }^{12}$ terjadi pelebaran sulci ipsilateral, dilatasi ventrikel dan ipsilateral dan ruang siternal, serta penebalan tulang unilateral. Gejala klinis DDMS bervariasi, diantaranya wajah asimetri, kejang, hemiparesis kontralateral, retardasi mental, gangguan belajar, gangguan bicara dll. Kejang dapat berupa fokal, bisa bersifat umum. DDMS lebih sering terjadi pada laki-laki dibanding wanita, dan lesi pada sisi kiri lebih sering terjadi dibanding kanan. ${ }^{13,14}$ Pada pemeriksaan MRI pasien ini ditemukan hemiatrofi serebral dekstra, hipertrofi calvaria dekstra, dilatasi ventrikel, dengan gambaran klinis kejang berulang, hemiparesis sinistra, parese $\mathrm{N}$ VII,XII sinistra tipe sentral, dan gangguan belajar. Kekurangan pada artikel ini adalah tidak dilakukan test IQ untuk menyokong diagnosis retardasi mental pada pasien ini.

Pada gambaran radiologi, tampak hilangnya volume cerebral unilateral, yang menyebabkan gangguan kalvaria sebagai kompensasinya, seperti penebalan, hiperpneumatisasi di sinus paranasal dan mastoid. ${ }^{2}$ 
Pemeriksaan MRI otak terdapat tiga bentuk hemiatrofi serebral. ${ }^{15,16,17}$

1. adanya atrofi kortikal dan subkortikal difus.

2. adanya atrofi kortikal difus dan disertai dengan kista porencephalic.

3. Adanya infark sebelumnya dengan gliosis pada daerah teritorial arteri serebri media.

Pada kasus ini terdapat terjadi hemiatrofi serebral campuran bentuk 2 dan 3 dimana terdapat kista porencephalic disertai dengan gliosis.

Diagnosis banding DDMS dapat berupa germinoma ganglia basal, Sturge Weber Syndrome, dan Rasmussen Ensefalitis. Dengan anamnesis dan pemeriksaan fisik yang baik dan ditunjang dengan pemeriksaan radiologi, DDMS dapat ditegakkan dan diagnosis banding dapat disingkirkan. $7,8,9$

Penatalaksanaan DDMS fokus kepada penatalaksanaan dan kontrol kejang dengan terapi anti kejang yang sesuai. Selain itu terapi lain yang dapat dilakukan adalah fisioterapi dan terapi bicara sangat berperan dalam terapi jangka panjang. Hemisferektomi merupakan pilihan untuk kasus pada anak dengan kejang berulang dan hemiplegi dengan angka keberhasilan $85 \%$ pada kasus tertentu. ${ }^{18,19,20}$ Pada kasus ini pasien masuk dengan status epileptikus, dan diatasi dengan pemberian fenitoin 15 $\mathrm{mg} / \mathrm{kg}$ BB drip dalam $50 \mathrm{cc} \mathrm{NaCl}$ 0,9\% dengan kecepatan $99 \mathrm{cc} / \mathrm{jam}$. Pasien bebas kejang dalam rawatan pasca pemberian fenitoin drip, dan dilanjutkan dengan fenitoin $300 \mathrm{mg} /$ hari. Pulang rawatan, pasien masih ada kejang umum tonik klonik sekitar 1-2 kali dalam sebulan, dan setelah kejang pasien sadar. Pada kasus ini setelah dikonsulkan ke bagian bedah saraf, tidak ada tindakan operasi di bagian bedah saraf, karena kista yang terbentuk merupakan akibat dari atrofi serebral, dan tidak akan menyebabkan peningkatan volume otak.

Prognosis akan lebih baik jika onset hemiparesis terjadi pada usia 2 tahun atau lebih dan tidak ada prolonged ataupun kejang berulang. ${ }^{13}$ Pada kasus ini prognosis buruk karena kejang terjadi pada saat pasien berumur kurang dari satu tahun, berulang, dan hemiparesis muncul saat pasien berumur satu tahun.

\section{SIMPULAN}

Pada pasien ini yang harus diedukasi adalah tidak boleh putus obat kejang, dan hindari faktor-faktor yang memicu kejang.

\section{SARAN}

DDMS merupakan kasus yang jarang terjadi, sehingga sangat memungkinkan terjadi kesalahan dalam mendiagnosis, maka diperlukan keterampilan dalam melakukan anamnesis, pemeriksaan fisik dan pemeriksaan penunjang yang tepat agar dapat dilakukan penatalaksanaan yang optimal.

\section{DAFTAR PUSTAKA}

1. Dyke CG, Davidoff LM, Masson CB. Cerebral hemiatrophy and homolateral hypertrophy of the skull and sinuses. Surg Gynecol Obstet. 1933; 57: 588-600.

2. Sharma S, Goyal I, Negi A, Sood RG, Jhobta A, Surya M. Dyke-Davidoff-Masson syndrome. Ind $\mathrm{J}$ Radiol Imag. 2006;16:165-6.

3. Ono K, Komai K, Ikeda T. Dyke-Davidoff-Masson syndrome manifested by seizure in late childhood: a case report. J Clin Neurosci. 2003;10:367-71.

4. Shetty DS, Lakhkar BN, John JR. Dyke-DavidoffMasson syndrome. Neurol india. 2003;51:136.

5. Narain NP, Kumar R, Narain B. Dyke-DavidoffMasson syndrome. Indian Pediatr. 2008;45:927-8.

6. Singh P, Saggar K, Ahluwalia A. Dyke-DavidoffMasson syndrome: classical imaging findings. J Pediatr Neurosci. 2010;5(2):124-5.

7. Sener RN, Jinkis JR. MR of craniocerebral hemiatrophy. Clin Imaging.1992;16: 93-7.

8. Rao KCVG. Degenerative diseases and hydrocephalus. In: Lee SH, Rao KCVG, Zimmerman RA, editors. Cranial MRI and CT. 4th eds. New York: McGraw-Hill; 1999.

9. Zilkha A. CT of cerebral hemiatrophy. Am J Roentgenol. 1980;135:259-62.

10. Stred SE, Byrum CJ, Bove EL, Oliphant M: Coarctation of midaortic arch presenting with monoparesis. Ann Thorac Surg. 1986;42:210-2.

11. Graham A, Molnar Z. Development of the nervous system. In: Standring S, editor. Gray's Anatomy. 
40th Ed. London, Churchill Livingstone, Elsevier, 2008,p.385.

12. Pendse NA, Bapna $P$, Menghani V, Diwan A. Dyke-Davidoff-Masson syndrome. Indian J Pediatr. 2004;71:943.

13. Unal O, Tombul T, Cirak B, Anlar O, Incesu L, Kayan M. Left hemisphere and male sex dominance of cerebral hemiatrophy (DykeDavidoff-Masson syndrome). Clin Imaging. 2004; 28:163-5.

14. Kälviäinen $R$, Salmenperä $T$ : Do recurrent seizures cause neuronal damage? A series of studies with MRI volumetry in adults with partial epilepsy. Prog Brain Res. 2002;135:279-95.

15. Shen WC, Chen CC, Lee SK, Ho YJ, Lee KR Magnetic resonance imaging of cerebral hemiatrophy. J Formos Med Assoc. 1993; 92 (11): 995-1000.

16. Qiu BP, Shi CH: Silver-Russel syndrome: a case report. World J Pediatr. 2007;3:68-70.

17. Jacoby CG, Go RT, Hahn FJ: Computed tomography in cerebral hemiatrophy. AJR Am J Roentgenol. 1977;129:5-7.

18. Behera MR, Patnaik S, Mohanty AK. DykeDavidoff-Masson syndrome. J Neurosci Rural Pract. 2012;3(3):411-3.

19. Van Empelen R, Jennekens-Schinkel A, Buskens E, Helders PJ, van Nieuwenhuizen O. Dutch collaborative epilepsy surgery programme: functional consequences of hemispherectomy. Brain. 2004;127:2071-9.

20. Narain NP, Kumar R, Narain B. Dyke-DavidoffMasson syndrome. Indian Pediatr 2008;45:927-28. 